\title{
Revamping Health Professionals Education for Stronger Health Systems
}

With an emerging transformation in global health from 'diseases' to 'Health Systems', there is increased recognition that Health Systems need to be resilient and receptive to the accelerated demographic and epidemiological transition, posing unconventional health challenges. Health System strengthening is also crucial for progressing towards Universal Health Coverage which is an intrinsic attribute of health related SDGs (2030).

In light of contemporary threats to health security, Health systems are becoming more complex and placing supplementary demands on the Health Workforce which is one of the key components of health systems. Pakistan has been categorized as one of 57 countries that are facing an HRH (Human Resource for Health) crisis i.e. that its health workforce is below the threshold level defined by WHO, required to deliver the essential health interventions to attain the Sustainable Development Goals (UN) by 2030. ${ }^{1}$ The crisis is complex and is related not just to the quantity but the quality, efficiency and effectiveness of the health workforce.

In a series of studies about Health Professionals education, the landmark 1910 Flexner Report ${ }^{2}$ triggered revolutionary reform in Health Professionals education by consolidating modern science into the curricula at universities, equipping the health professionals with the knowledge that contributed to enhanced life expectancy and improved quality of life in the $20^{\text {th }}$ century. Marking the centenary of the reform initiative, the Lancet Commission on 'Education of Health Professionals for the $21^{\text {st }}$ Century' accented the fact that professional medical education especially in developing countries, has not kept pace with emerging challenges because of obsolete and inert curricula that has led to production of valueless and ill equipped graduates who have not been able to address the contextual challenges effectively. ${ }^{3}$

According to the commission some of the imping- ing issues include weak leadership to improve health system performance, persistent mismatch of competencies to individual patient and population needs, limited technical focus without broader contextual understanding, predominant clinical orientation at the expense of primary health care, intermittent episodic encounter of the patient with clinic rather than a 'continuum of care' approach etc.

The Commission draws attention to 'three generations' of Health Professional education reform in the past century starting with a science based curriculum in the first generation (start of the $20^{\text {th }}$ century) followed by problem based instructional innovation (midcentury). Authorities emphasize that a third generation of reform is now required that employs a systems approach for improving health system performance and adapts core professional competencies to specific contexts while drawing on global knowledge. They maintain that actualization of this vision will require a series of instructional and institutional reforms, which should be guided by transformative learning which is the highest of three successive levels, moving from informative to formative to transformative learning. Informative learning is about acquisition of knowledge and skills with the objective to produce experts. Formative learning is about socializing students around values to produce professionals. Transformative learning is about developing leadership attributes; its purpose being production of enlightened and cultivated change agents. Effective education builds each level on the previous one. As a valued outcome, transformative learning involves three fundamental shifts: from fact memorization to searching, analysis, and synthesis of information for decision making; from seeking professional credentials to achieving core competencies for Effective teamwork in health systems; and from non-critical adoption of educational models to innovative adoption of global resources to address local priorities. ${ }^{3}$ 
Pursuance of these reforms requires leadership from within the academic and professional communities, increased investments and stewardship followed by shared learning by supporting evaluation and strengthening of research to build the knowledge base about which innovations work in which settings. It is critically important to subscribe to the vision and recommendations of the Commission for development of cadres of skilled, competent and motivated health professionals who can in due course, be agents of change within their domains and work towards addressing the daunting health challenges of our times.

(Adapted from The Lancet Commission on 'Education of Health Professionals for the $21^{\text {st }}$ Century, 2010)

\section{References}

1. Global Health Workforce Alliance. Scaling-up, saving lives. Geneva: World Health Organization, 2008.

2. Flexner A. Medical education in the United States and Canada: a report to the Carnegie Foundation for the Advancement of Teaching. New York: The Carnegie Foundation for the Advancement of Teaching, 1910.

3. Julio Frenk, Lincoln Chen, Zulfiqar A. Bhutta et al. Health professionals for a new century: transforming education to strengthen health systems in an intedependent world. Lancet, 2010; 376: 1923-58.

Dr. Saira Tariq

Assistant Editor, Annals of KEMU Assistant Professor of Community Medicine King Edward Medical University, Lahore 